\title{
A Randomized Controlled Trial of Green Tea Beverages on the in vivo Radical Scavenging Activity in Human Skin
}

\author{
Inna Megow Maxim E. Darvin Martina C. Meinke Jürgen Lademann \\ Charité - Universitätsmedizin Berlin, corporate member of Freie Universität Berlin, Humboldt-Universität zu Berlin, \\ and Berlin Institute of Health, Center of Experimental and Applied Cutaneous Physiology (CCP), Department of \\ Dermatology, Berlin, Germany
}

\section{Keywords}

Free radicals · Oxidative stress · Green tea · Antioxidants .

Polyphenols · Electron paramagnetic resonance

spectroscopy · Resonance Raman spectroscopy more effective than the common Yabukita tea. Conclusion: The results show that green tea enhances the radical scavenging capacity of the skin and support the hypothesis that green tea may offer protection against cutaneous oxidative stress.

(c) 2017 S. Karger AG, Basel

\begin{abstract}
Background: Oxidative stress plays an important role in the pathogenesis of various skin diseases. Thus, the antioxidant network of the skin relies on the uptake of exogenous antioxidants to ensure cell protection against radical formation. Green tea is one of the main sources of polyphenolic antioxidant compounds, but only few data are available on its cutaneous antioxidant effects. Methods: The radical scavenging properties of Benifuuki and Yabukita green tea were investigated in the human skin. Thirty-two participants who met the inclusion criteria were randomized to consume 3 cups per day of either Benifuuki tea, Yabukita tea, or water (control group) for 2 weeks. Electron paramagnetic resonance (EPR) spectroscopy was applied to measure the radical scavenging capacity of the skin in vivo before and after the intervention. Results: Both Yabukita and Benifuuki tea led to an increase in the radical scavenging activity of the skin by 28 and 29\%, respectively, and the difference was significant when compared to the control group. Benifuuki tea, previously reported to be superior in bioavailability due to a highly absorbable methylated catechin, did not prove to be
\end{abstract}

\section{KARGER}

(C) 2017 S. Karger AG, Basel

E-Mail karger@karger.com

www.karger.com/spp

\section{Introduction}

Radical formation is an important factor in the pathogenesis of skin diseases [1]. Free radicals derive from numerous internal and external sources, including aerobic cellular metabolism, air pollution [2], and solar irradiation in the ultraviolet, visible, and near-infrared spectrum [3-5]. Though low concentrations of free radicals are required for cell signaling [6] and physiological inflammatory reactions [7], excessive free radical production can result in cellular damage and the development of skin cancer [8] or premature skin aging [9]. Recent research suggests that oxidative stress may also be a key player in chronic inflammatory skin diseases, including psoriasis [10], atopic dermatitis [11], and acne [2].

To prevent skin damage due to oxidative stress, the skin possesses an elaborated antioxidant network to neutralize radicals [8]. While some antioxidants like catalase, glutathione, and superoxide dismutase are naturally syn-

Inna Megow or Jürgen Lademann

Department of Dermatology, Venerology, and Allergology Charité-Universitätsmedizin Berlin, Charitéplatz 1 DE-10117 Berlin (Germany)

E-Mail inna.megow@ charite.de or juergen.lademann@ charite.de 
thesized by the body, most have to be obtained from the diet.

Green tea, being a very popular beverage, is a major source of antioxidant polyphenolic components, especially catechins and flavonols $[12,13]$. The most abundant and powerful antioxidant among the catechins, accounting for around $50 \%$ of total catechins in green tea, is epigallocatechin-3-O-gallate (EGCG) [14]. The flavonol quercetin is an equally strong antioxidant as EGCG [15]. Other catechins contributing to the antioxidant potential of green tea include epicatechin, epicatechin-3-Ogallate and epigallocatechin [16]. Apart from their intrinsic antioxidant properties, green tea polyphenols were shown to stimulate the transcription of antioxidant enzyme genes, suggesting a tight connection between exogenous and endogenous antioxidants [17].

The antioxidant effect of green tea is by far not the only mechanism of action that is beneficial to human skin health [18]. Green tea polyphenols were shown to induce apoptosis in human epidermoid carcinoma cells [19] and human melanoma cells [20]. Topical application of EGCG on the skin of volunteers was effective in inhibiting UVinduced inflammatory reactions, lipid peroxidation, and DNA damage [21, 22]. Preventive effects of green tea polyphenols against photoaging are mediated by antimelanogenic and antiwrinkle mechanisms and by the inhibition of UV-induced immunosuppression [23]. Furthermore, green tea polyphenols possess antiviral properties and have been found effective in the treatment of herpes simplex labialis infections [24] and condylomata accuminata [25]. These findings suggest that green tea may be suitable for the prevention and treatment of various skin diseases.

However, the results of in vitro and topical application may not be transferrable to orally administered substances, as green tea polyphenols undergo numerous biotransformation processes [12]. The knowledge of the underlying pharmacokinetics is crucial for the understanding of the biological effects of orally administered green tea polyphenols [26-29]. A large number of metabolites deriving from methylation, glucuronidation, and colonic ring fission have been described so far [12]. The impact of these biotransformation processes on the antioxidant potential, the pharmacological activity, and the cutaneous bioavailability of the metabolites is not yet clearly understood.

Only 2 cutaneous bioavailability studies have investigated green tea metabolites so far. The most recent study identified 26 green tea metabolites in plasma after oral green tea administration, while 20 metabolites were found in skin blister fluid [30]. In contrast, only 7 substances could be found in skin biopsies, including quercetin and 5 - $\left(3^{\prime}, 4^{\prime}\right.$-dihydroxyphenyl $)-\gamma$-valerolactone (M6), a ring fission catechin metabolite derived from gut microbiota [31]. Contrary to the results of the previous work of the same group [32], EGCG was not identified in skin biopsies. However, as EGCG is reported to undergo hydrolysis in vivo [33], it is likely to contribute to the antioxidant status of the skin via its hydrolysis product gallic acid and the colonic metabolite M6, which themselves exert antioxidant activity $[34,35]$. These results suggest that some green tea metabolites are incorporated into human skin, while others are not, but the data are inconclusive.

Similarly, clinical trials examining the photoprotective effect of oral green tea administration have yielded conflicting results [32, 36-38]. Furthermore, clinical and epidemiological studies investigating the biological effects of orally administered green tea tend to produce inconclusive results in general, regardless of the topic of investigation $[39,40]$.

To understand these findings, it is important to consider the results from bioavailability studies, which unanimously report large interindividual differences $[28,30$, 41-43]. Genetic predisposition [44] and nutrition patterns interacting with polyphenol absorption $[40,45]$ are among the factors that were postulated to contribute to the interindividual variations. The microbiome hypothesis seeks to explain the varying effects of green tea administration through the impact of the gut microbiome $[28,42]$. Not only do colonic ring fission valerolactones account for almost $90 \%$ of excreted catechin metabolites, they also show wide variability that is likely to result from differences in the colonic microflora [42].

It was furthermore postulated that the choice of a particular green tea cultivar may influence bioavailability. As the catechin composition is different for each cultivar and pharmacokinetics differ strongly among catechins [26], several studies have focused on the cultivar Benifuuki which contains highly absorbable methylated catechins such as epigallocatechin-3-O-(3-O-methyl)-gallate (EGCG3" Me). Compared to EGCG, EGCG3" ${ }^{\prime \prime} \mathrm{Me}$ is reported to have a significantly higher bioavailability [46]. Benifuuki tea also proved to be more effective in treating allergies [47] than the common Yabukita tea, a cultivar that does not contain any methylated EGCG.

These findings suggest that the use of Benifuuki tea may be suitable as a means to increase the bioavailability and efficacy of green tea in clinical trials. However, as cutaneous bioavailability data are lacking for EGCG3" $\mathrm{Me}$ 
and its metabolic fate in humans has not been described yet, it is not clear whether EGCG3"Me or its metabolites are incorporated into human skin.

One possibility to investigate this issue is to determine the radical scavenging capacity of the skin in vivo with electron paramagnetic resonance (EPR) spectroscopy [48]. Previous studies involving in vivo EPR spectroscopy showed that the cutaneous radical scavenging capacity can be increased by the administration of vitamin C, Aronia extract, and carotenoids [49].

To determine the effects of oral green tea administration on the antioxidant status of human skin, and to compare the cutaneous radical scavenging effects of Benifuuki tea and Yabukita tea, we conducted a randomized, partially double-blind, controlled pilot trial.

\section{Materials and Methods}

\section{Participants}

A total of 37 healthy volunteers (aged between 20 and 55 years, 21 women and 16 men) were recruited. Individuals aged between 18 and 60 years who did not meet any of the following exclusion criteria were admitted: skin diseases or skin barrier disorders, metallic implants in the forearms, allergies, food intolerances, pregnancy, and lactation.

\section{Study Design}

Participants were randomly assigned to one of the following 3 groups: control group, or Yabukita or Benifuuki tea groups. All subjects consumed $600 \mathrm{~mL}$ of beverages per day for 2 weeks, with EPR spectroscopy and resonance Raman spectroscopy performed at baseline and after 14 days.

Participants of the green tea groups were provided with uniform boxes containing organic Benifuuki or Yabukita tea leaves from the Japanese prefecture Kagoshima. The boxes were labeled with an allocation number to ensure blinding of the study investigator and the participants. The subjects assigned to the tea groups were instructed to drink 3 cups of fresh self-brewed green tea prepared according to the instructions of the tea manufacturer $(2 \mathrm{~g}$ of tea leaves infused for $1.5 \mathrm{~min}$ in $200 \mathrm{~mL}$ of hot water). The total tea consumption of the volunteers was assessed by weighing the boxes at baseline and after 2 weeks. Participants of the control group were requested to drink 3 cups of water per day.

The subjects were instructed to maintain their lifestyle and usual diet, except for the 3 additional cups of green tea or water (control group) per day.

\section{EPR Spectroscopy}

EPR spectroscopy uses the interaction of a paramagnetic molecule with an external magnetic field to assess the radical scavenging capacity of the skin. As paramagnetic species contain unpaired electrons, the application of the magnetic field leads to the Zeeman effect, a split in the energy levels of the molecule. This enables an absorption of microwave radiation, if the microwave energy matches the distance between the 2 Zeeman levels [50]. Using a topically administered free radical with an unpaired electron as EPR marker, the microwave absorption of the radical molecules can be measured and recorded in an EPR spectrum. As the concentration of the free radical decreases over time due to redox reactions in the skin, a decay in the EPR signal intensity will occur [51].

The L-band EPR spectrometer LBM MT 03 (Magnettech, Berlin, Germany) was used to perform the in vivo measurements with the following parameters: microwave frequency $-1.3 \mathrm{GHz}$, magnetic field $-46 \mathrm{mT}$, sweep width $-8 \mathrm{mT}$, sweep time $-10 \mathrm{~s}$, and modulation amplitude $-0.15 \mathrm{mT}$.

TEMPO (2,2,6,6-tetramethyl-1-piperidinyloxyl), a nitroxide free radical purchased from Sigma-Aldrich (Steinenheim, Germany), was used as marker for EPR spectroscopy. The $30 \mathrm{~mm}$ solution was prepared using a 1:1 mixture of ethanol and water.

The right inner forearm was chosen as measuring spot for all participants. Prior to applying TEMPO on the skin, an ethanolsoaked paper towel was used to clean the skin surface and, if necessary, hairs were carefully removed with medical scissors. The cutaneous application of TEMPO was performed placing $50 \mu \mathrm{L}$ of the freshly prepared TEMPO solution on a filter paper (SmartPractice, Phoenix, AZ, USA) and occluding it with a 12-mm Finn chamber (SmartPractice) for $10 \mathrm{~min}$. After the removal of the Finn chamber and the filter paper, residual TEMPO solution was wiped off from the skin with a paper towel. The forearm was placed beneath the surface coil and immobilized; a thin cover glass (R. Langenbrinck, Emmendingen, Germany) separated the skin from the surface coil.

During the 14 min of EPR measurement, 4 scans per min were recorded, and a mean spectrum of 8 scans was evaluated to increase the signal-to-noise ratio. EPR intensity of TEMPO was derived from the height of the central line of the mean spectra and normalized to the baseline value at $0 \mathrm{~min}$. The rate constant $\mathrm{k}$ was calculated using the exponential function $\mathrm{I}(\mathrm{t})=\mathrm{I}_{0} \mathrm{e}^{-\mathrm{kt}}$. EPR measurements were performed at least twice to ensure reproducible results with a rate constant deviation of not more than $30 \%$.

\section{Resonance Raman Spectroscopy}

Resonance Raman spectroscopy is a noninvasive and quick method to measure the concentration of cutaneous carotenoids in vivo [52]. It is based on the inelastic scattering of monochromatic light after interaction with a molecule, resulting in a molecularvibration-related shift in the emitted frequency of the photon. With the knowledge of a molecule's Raman spectrum, it is possible to identify the molecule in a tissue and even measure its absolute concentration [53].

To determine the total carotenoid content and the lycopene content of the skin, measurements were performed on the palm of the volunteers using 488- and 514.5-nm wavelengths. Blue light at 488 -nm wavelength is used to excite all carotenoids, thus providing information on the total carotenoid content of the skin, while green light at $514.5 \mathrm{~nm}$ will excite mainly lycopene [54]. An argon laser was used as a source of excitation. Mean values of 6 measurements per wavelength were calculated.

\section{Questionnaire}

All participants were asked to complete a questionnaire at baseline and after 2 weeks to evaluate possible effects of lifestyle on the antioxidant status. In addition to sun exposure, stress, mood, and health, a food frequency questionnaire containing 26 common fruits and vegetables as well as different types of teas and juices was used to assess the intake of foods and beverages. A numerical value 
Table 1. Characteristics of the study population

\begin{tabular}{|c|c|c|c|c|}
\hline & $\begin{array}{l}\text { Water } \\
(n=10)\end{array}$ & $\begin{array}{l}\text { Yabukita } \\
(n=11)\end{array}$ & $\begin{array}{l}\text { Benifuuki } \\
(n=11)\end{array}$ & $\begin{array}{l}\text { Total } \\
(n=32)\end{array}$ \\
\hline \multicolumn{5}{|l|}{ Gender } \\
\hline Males & 4 & 6 & 5 & 15 \\
\hline Females & 6 & 5 & 6 & 17 \\
\hline \multicolumn{5}{|l|}{ Age, years } \\
\hline Mean \pm SD & $31 \pm 11$ & $29 \pm 9$ & $30 \pm 8$ & $31 \pm 10$ \\
\hline Range & $21-52$ & $23-55$ & $20-44$ & $20-55$ \\
\hline \multicolumn{5}{|l|}{ Body mass index } \\
\hline$<20$ & 0 & 0 & 3 & 3 \\
\hline $20-25$ & 9 & 9 & 6 & 24 \\
\hline$>25$ & 1 & 2 & 2 & 5 \\
\hline \multicolumn{5}{|l|}{ Smoking status } \\
\hline Smokers & 2 & 1 & 1 & 4 \\
\hline Nonsmokers & 8 & 10 & 10 & 28 \\
\hline
\end{tabular}

Table 2. Rate constants and carotenoid values measured at baseline and after 2 weeks (means \pm SD)

\begin{tabular}{|c|c|c|c|c|}
\hline & Water & Yabukita & Benifuuki & Total \\
\hline \multicolumn{5}{|c|}{ Rate constant $\mathrm{k}, 10^{-2} \times \mathrm{min}^{-1}$} \\
\hline Baseline & $5.2 \pm 1.2$ & $4.1 \pm 1.6$ & $4.2 \pm 1.4$ & $4.5 \pm 1.5$ \\
\hline 2 weeks & $4.8 \pm 1.7$ & $5.0 \pm 1.9$ & $5.1 \pm 1.6$ & $5.0 \pm 1.6$ \\
\hline \multicolumn{5}{|c|}{ Total carotenoids, arbitrary units $\times 10^{-4}$} \\
\hline Baseline & $5.7 \pm 2.0$ & $4.3 \pm 1.0$ & $5.5 \pm 2.3$ & $5.1 \pm 1.9$ \\
\hline 2 weeks & $5.2 \pm 1.6$ & $4.5 \pm 1.3$ & $5.5 \pm 2.0$ & $5.1 \pm 1.7$ \\
\hline \multicolumn{5}{|c|}{ Lycopene, arbitrary units $\times 10^{-4}$} \\
\hline Baseline & $1.7 \pm 0.5$ & $1.3 \pm 0.4$ & $1.6 \pm 0.4$ & $1.5 \pm 0.5$ \\
\hline 2 weeks & $1.9 \pm 0.5$ & $1.5 \pm 0.5$ & $1.7 \pm 0.7$ & $1.7 \pm 0.6$ \\
\hline
\end{tabular}

representing the average intake per month was assigned to every frequency category, and the values were summed up to a score. An attitude score representing 5 different degrees of stress was used to assess the mental stress level of participants.

\section{Statistical Analysis}

Statistical analysis was performed with IBM SPSS Statistics 22. The Shapiro-Wilk test was used to analyze distribution properties of the acquired data. Normally distributed data were analyzed with the paired-sample $t$ test for related data and the independent-sample $t$ test for independent data. For nonnormally distributed data, the Wilcoxon test was performed on related samples, while the Mann-Whitney $U$ test was run to analyze independent samples. The Kendall $\tau_{\mathrm{b}}$ test was used to investigate correlations between nonnormally distributed variables. A $p$ value (2-tailed) of $\leq 0.05$ was considered statistically significant.

\section{Results}

\section{Volunteers}

A total of 37 subjects were recruited for the study. One volunteer from the Yabukita group dropped out before completing the study and another subject from the same group had to be excluded as it was not possible to perform reproducible EPR measurements at the second visit. Another 3 subjects ( 1 in the control group and 2 in the Benifuuki group) had to be excluded as they underwent antiinfective treatment for moderate-to-severe infections which occurred during the last week of the study. Consequently, 32 subjects were included in the study analysis, and their characteristics are shown in Table 1.

\section{EPR Measurements}

The mean baseline rate constant of all volunteers was $(4.5 \pm 1.5) \times 10^{-2} \mathrm{~min}^{-1}$, with no significant differences 


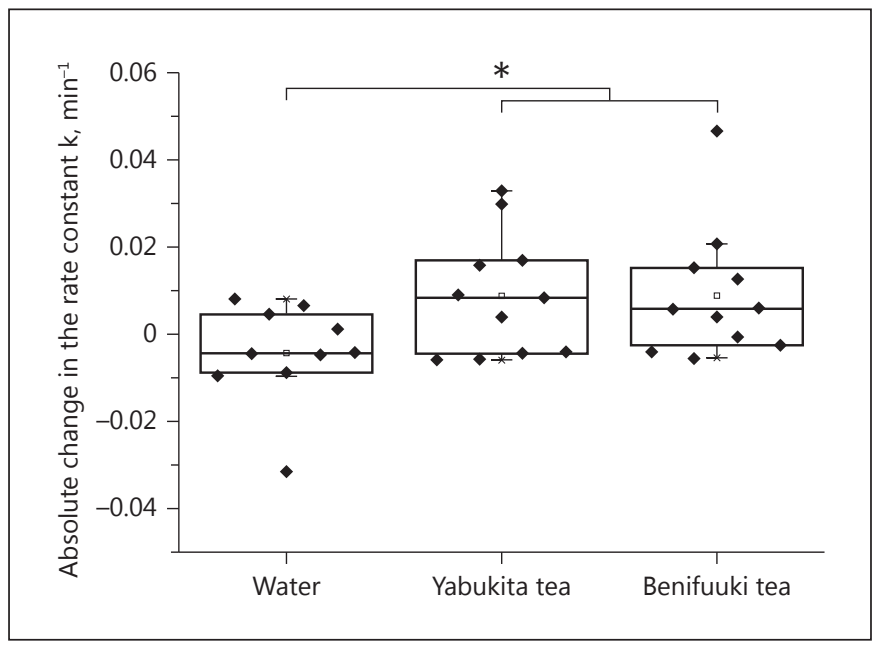

Fig. 1. Boxplots of the absolute differences in rate constants after 2 weeks of drinking water, Yabukita tea, or Benifuuki tea. ${ }^{*} p \leq 0.05$.

between the 3 study groups (Table 2). After 2 weeks, both tea groups showed a significant increase in the radical scavenging capacity when compared to the control group (Fig. 1). The individual rate constant $\mathrm{k}$ increased by $28 \%$ in the Yabukita group and by $29 \%$ in the Benifuuki group while in the control group no increase was found. The maximum individual increase in the rate constant was $102 \%$ in the Yabukita group and $173 \%$ in the Benifuuki group, but only $18 \%$ in the control group. However, 5 participants of the Yabukita group and 6 of the Benifuuki group showed either a rate constant decrease or an increase of less than $18 \%$.

\section{Raman Measurements}

No significant changes were observed in the total carotenoid content of the skin (Table 2). The lycopene content increased, though not significantly, in all groups. Noticeable gender-related differences in the baseline carotenoid content were present, with a $44 \%$ higher total carotenoid content $(p=0.002)$ in women. Lycopene values were $23 \%$ higher in women $(p=0.057)$, though the difference was not statistically significant. A strong correlation between baseline lycopene and the total carotenoid content was present $\left(\tau_{\mathrm{b}}=0.633, p<0.001\right)$.

\section{Questionnaire}

The evaluation of the food frequency questionnaire revealed no significant changes in the food intake of volunteers during the 2 weeks. No significant correlation could be found between the intake of vegetables and fruits and

Green Tea Increases Radical Scavenging

Activity in the Skin the baseline rate constant or carotenoid content of the skin. A weak but significant positive correlation between reported mental stress levels and the rate constant $\left(\tau_{\mathrm{b}}=0.298\right.$, $p=0.03$ ) was present. However, statistical analysis revealed no relationship between stress levels and the effects of green tea supplementation. Two subjects of the Yabukita group and 3 of the Benifuuki group reported symptoms of illness (in most cases common cold) during the last week of the study. Remarkably, 4 of the subjects affected by illness also showed a decrease in the rate constant.

\section{Discussion}

The aim of the pilot study was to investigate the effects of green tea consumption on the radical scavenging capacity of human skin. Furthermore, it was to be determined whether Benifuuki tea, which is reported to contain a catechin with a very high bioavailability [46], would prove to be more effective than Yabukita tea. Both Yabukita and Benifuuki tea led to a significant increase of almost 30\% in the rate constant of the EPR signal decay compared to the control group. These results indicate a higher antioxidant content of the skin in the subjects of the tea groups, leading to a faster decrease in the EPR signal of the radical TEMPO. As cutaneous bioavailability studies showed that green tea polyphenols and their metabolites are incorporated into human skin $[30,32]$, the increase in the rate constant might be a result of the direct antioxidant effects of green tea polyphenols in the skin. Polovka et al. [55] used EPR spectroscopy to demonstrate that green tea is an effective scavenger of the radicals DPPH (2,2-diphenyl-1-picrylhydrazyl) and 4-hydroxyTEMPO in vitro. Furthermore, polyphenols may provide additional indirect antioxidant effects by stimulating the transcription of endogenous antioxidants [17]. Quercetin was shown to upregulate the production of glutathione [56] and to induce phase II antioxidant enzymes through Nrf2-dependent gene expression [57]. Results from a clinical trial of green tea in patients with the metabolic syndrome showed an increase in blood glutathione levels, but other antioxidant enzymes like glutathione peroxidase and catalase remained unaffected [58]. In a trial examining the photoprotective effects of topical EGCG application, EGCG was found to inhibit UV-induced depletion of cutaneous glutathione [22]. It is important to consider the effects of green tea polyphenols on glutathione metabolism, as glutathione, alongside with ascorbic acid, is reported to be one of the main reductors of TEMPO in human skin [51].

Skin Pharmacol Physiol 2017;30:225-233

DOI: $10.1159 / 000477355$ 
However, it should be noted that the mechanisms of radical scavenging are very complex. TEMPO, which readily accepts electrons and forms EPR-silent hydroxylamine, is considered very suitable to measure tissue antioxidant activity [59]. However, a loss of the EPR signal can also occur due to the destruction of TEMPO by certain radicals, especially hydroxyl radicals, as well as carbon-centered and peroxyl radicals [51]. On the other hand, green tea polyphenols may also exert prooxidant activity and lead to oxidative stress. The impact of these prooxidant effects is not yet clear, though it was postulated that the induction of low-level oxidative stress by green tea may be responsible for the activation of endogenous antioxidant pathways and thus be in fact beneficial [14]. Due to the intricate and contradicting nature of these mechanisms, results of EPR measurements should be interpreted with care.

The effects of green tea on the radical scavenging capacity of the skin were comparable to those of vitamin C, Aronia extract, and carotenoids, which increased the rate constant by $22-37 \%$ in previous studies [60-62]. However, this is the first study to show that a natural product as green tea, without any artificially added antioxidants, is capable of increasing the cutaneous radical scavenging activity.

Despite the good bioavailability and high antioxidant activity of EGCG3"Me [63], no difference in the outcomes of the Yabukita and Benifuuki tea groups could be observed, suggesting that the methylated catechins of Benifuuki tea offer no additional benefit to the cutaneous antioxidant effects of green tea. Not all green tea polyphenols are equally efficient in activating antioxidant pathways [64], and only few data are available on the pharmacological effects of EGCG3"Me. Furthermore, no study has investigated the incorporation of EGCG3" Me into human skin so far. Further research is needed to clarify the role of the different green tea polyphenols and their metabolites for the antioxidant network of the skin.

While the mean individual increase in the rate constant was nearly $30 \%$ in both tea groups, large interindividual differences were observed, which could be explained by considerable variations in bioavailability shown in previous studies. Calani et al. [43] reported a mean green tea bioavailability of $62 \%$ in a study of 20 participants, where 4 subjects reached a 100\% bioavailability and 5 subjects showed a bioavailability of less than $30 \%$. It is noticeable that a high number of subjects from the Yabukita and Benifuuki tea groups showed only a small increase or even a decrease in the rate constant, raising the question of responsiveness to green tea catechins as discussed by Mereles and Hunstein [40]. If the maximum individual rate constant increase of $18 \%$ in the control group is taken as cutoff value for the responding status, half of the subjects in both green tea groups could be classified as nonresponders. However, the decrease in the rate constant observed in 4 of 5 participants affected by illness during the study indicates a negative influence of illness on the radical scavenging capacity of the skin, possibly due to a decrease in cutaneous antioxidants as reported in previous studies $[65,66]$. Furthermore, considering that biomarkers of green tea consumption were not monitored in blood or urine, it is not clear how many of the nonresponders were noncompliant.

Analysis of the questionnaire revealed a weak correlation between mental stress levels and the baseline rate constant. Psychological stress may cause cellular oxidative stress through activation of the hypothalamic-pituitary-adrenal axis and cytokine release [67]. However, mild or moderate stress can also lead to an upregulation of glutathione synthesis, presumably as a protective measure to counteract excessive radical formation [68]. Therefore, an increase in cutaneous glutathione levels could lead to a faster TEMPO scavenging in volunteers who encountered psychological stress.

The total carotenoid content and the lycopene content did not change significantly in any of the groups, which is in accordance with previous studies investigating the antioxidant status after green tea ingestion. An 8-week study conducted on patients with the metabolic syndrome reported that green tea increased plasma antioxidant capacity, but did not affect serum carotenoids or tocopherols [58]. Similarly, green tea polyphenols did not change plasma $\beta$-carotene and vitamin $C$ in smokers [69].

The finding that oral administration of green tea may alter the antioxidant status of the skin has important implications for the use of green tea in dermatology, which so far was mostly limited to topical application. Sinecatechins (green tea extract) ointment has been found effective in the therapy of condylomata accuminata, being the first botanical drug approved for prescription by the US Food and Drug Administration [70]. Similarly, the topical administration of green tea extract has yielded promising results in the treatment of rosacea, acne, and atopic dermatitis [70]. However, as evidence arises that orally administered green tea may exert biological effects in the skin, further research is needed to evaluate the effectiveness of green tea supplementation in the treatment and prevention of dermatological conditions, especially those associated with oxidative stress. 
The limitations of this pilot study include the lack of blinding of the control group against the green tea groups as well as a small sample size and short duration of the study. Previous EPR spectroscopy studies suggested that hydrophilic substances such as vitamin $C$ will increase the antioxidant potential of the skin after 2 weeks of supplementation [61], while carotenoids as hydrophobic substances exert their effects fully only after 8 weeks [62]. Green tea polyphenols are intermediate in their hydrophobicity [71], with several components, including quercetin and epicatechin, considered to be rather lipophilic $[57,72]$. Therefore, further studies with a longer followup should be performed to investigate the kinetics of the cutaneous radical scavenging effects of green tea.

\section{Conclusion}

This 2-week pilot study provides novel insights into the role of green tea for the antioxidant network of the skin. It was shown that the daily administration of 3 cups of freshly prepared green tea can enhance the radical scavenging capacity of human skin. No differences were observed between the Benifuuki and the Yabukita tea group. These findings should be confirmed in larger trials, and the question of the effectiveness of oral green tea supplementation in dermatological conditions associated with oxidative stress should be addressed.

\section{Acknowledgments}

The work was supported by the Foundation "Skin Physiology" of the Donor Association for German Science and Humanities. We are grateful for the help of Sabine Schanzer, who provided randomization and blinding of the test substances.

\section{Statement of Ethics}

The study protocol was approved by the Ethics Committee of the Charite-Universitätsmedizin Berlin and performed in accordance with the ethical standards of the Declaration of Helsinki as revised in 1983. The written informed consent of all participants was obtained prior to the beginning of the study.

\section{Disclosure Statement}

The authors declare no conflicts of interest.

\section{References}

1 Bickers DR, Athar M: Oxidative stress in the pathogenesis of skin disease. J Invest Dermatol 2006;126:2565-2575.

2 Kim KE, Cho D, Park HJ: Air pollution and skin diseases: adverse effects of airborne particulate matter on various skin diseases. Life Sci 2016;152:126-134.

3 Akhalaya MY, Maksimov GV, Rubin AB, Lademann J, Darvin ME: Molecular action mechanisms of solar infrared radiation and heat on human skin. Ageing Res Rev 2014;16: $1-11$.

4 Robert C, Bonnet M, Marques S, Numa M, Doucet O: Low to moderate doses of infrared A irradiation impair extracellular matrix homeostasis of the skin and contribute to skin photodamage. Skin Pharmacol Physiol 2015; 28:196-204.

5 Lohan SB, Müller R, Albrecht S, Mink K, Tscherch K, Ismaeel F, Lademann J, Rohn S, Meinke MC: Free radicals induced by sunlight in different spectral regions - in vivo versus ex vivo study. Exp Dermatol 2016;25:380385 .

6 Remacle J, Raes M, Toussaint O, Renard P, Rao G: Low levels of reactive oxygen species as modulators of cell function. Mutat Res 1995;316:103-122.

Green Tea Increases Radical Scavenging Activity in the Skin
7 Fantone JC, Ward PA: Role of oxygen-derived free radicals and metabolites in leukocyte-dependent inflammatory reactions. Am J Pathol 1982;107:395-418.

8 Sander CS, Chang H, Hamm F, Elsner P, Thiele JJ: Role of oxidative stress and the antioxidant network in cutaneous carcinogenesis. Int J Dermatol 2004;43:326-335.

9 Miyachi Y: Photoaging from an oxidative standpoint. J Dermatol Sci 1995;9:79-86.

10 Lin X, Huang T: Oxidative stress in psoriasis and potential therapeutic use of antioxidants. Free Radic Res 2016;50:585-595.

$11 \mathrm{Ji} \mathrm{H}, \mathrm{Li}$ XK: Oxidative stress in atopic dermatitis. Oxid Med Cell Longev 2016;2016: 2721469.

12 Feng WY: Metabolism of green tea catechins: an overview. Curr Drug Metab 2006;7:755809.

13 Riemersma RA, Rice-Evans CA, Tyrrell RM, Clifford MN, Lean ME: Tea flavonoids and cardiovascular health. QJM 2001;94:277-282.

14 Lambert JD, Elias RJ: The antioxidant and pro-oxidant activities of green tea polyphenols: a role in cancer prevention. Arch Biochem Biophys 2010;501:65-72.
15 Heim KE, Tagliaferro AR, Bobilya DJ: Flavonoid antioxidants: chemistry, metabolism and structure-activity relationships. J Nutr Biochem 2002;13:572-584.

16 Roy MK, Koide M, Rao TP, Okubo T, Ogasawara Y, Juneja LR: ORAC and DPPH assay comparison to assess antioxidant capacity of tea infusions: relationship between total polyphenol and individual catechin content. Int J Food Sci Nutr 2010;61:109-124.

17 Masella R, Di Benedetto R, Varì R, Filesi C, Giovannini C: Novel mechanisms of natural antioxidant compounds in biological systems: involvement of glutathione and glutathionerelated enzymes. J Nutr Biochem 2005;16: 577-586.

18 Katiyar SK, Ahmad N, Mukhtar H: Green tea and skin. Arch Dermatol 2000;136:989-994.

19 Ahmad N, Feyes DK, Nieminen AL, Agarwal R, Mukhtar H: Green tea constituent epigallocatechin-3-gallate and induction of apoptosis and cell cycle arrest in human carcinoma cells. J Natl Cancer Inst 1997;89:1881-1886.

20 Nihal M, Ahmad N, Mukhtar H, Wood GS Anti-proliferative and proapoptotic effects of (-)-epigallocatechin-3-gallate on human melanoma: possible implications for the chemoprevention of melanoma. Int $\mathrm{J}$ Cancer 2005;114:513-521. 
21 Elmets CA, Singh D, Tubesing K, Matsui M, Katiyar S, Mukhtar H: Cutaneous photoprotection from ultraviolet injury by green tea polyphenols. J Am Acad Dermatol 2001;44: 425-432.

22 Katiyar SK, Afaq F, Perez A, Mukhtar H: Green tea polyphenol (-)-epigallocatechin3 -gallate treatment of human skin inhibits ultraviolet radiation-induced oxidative stress. Carcinogenesis 2001;22:287-294.

23 Roh E, Kim JE, Kwon JY, Park JS, Bode AM, Dong Z, Lee KW: Molecular mechanisms of green tea polyphenols with protective effects against skin photoaging. Crit Rev Food Sci Nutr 2017;57:1631-1637.

24 Zhao M, Zheng R, Jiang J, Dickinson D, Fu B, Chu TC, Lee LH, Pearl H, Hsu S: Topical lipophilic epigallocatechin-3-gallate on herpes labialis: a phase II clinical trial of AverTeaX formula. Oral Surg Oral Med Oral Pathol Oral Radiol 2015;120:717-724.

25 Tatti S, Stockfleth E, Beutner KR, Tawfik H, Elsasser U, Weyrauch P, Mescheder A: Polyphenon E: a new treatment for external anogenital warts. Br J Dermatol 2010;162:176184.

26 Manach C, Williamson G, Morand C, Scalbert A, Rémésy C: Bioavailability and bioefficacy of polyphenols in humans. I. Review of 97 bioavailability studies. Am J Clin Nutr 2005;81:230S-242S.

27 Lambert JD, Sang S, Yang CS: Biotransformation of green tea polyphenols and the biological activities of those metabolites. Mol Pharm 2007;4:819-825.

28 Lee MJ, Maliakal P, Chen L, Meng X, Bondoc FY, Prabhu S, Lambert G, Mohr S, Yang CS: Pharmacokinetics of tea catechins after ingestion of green tea and (-)-epigallocatechin3-gallate by humans: formation of different metabolites and individual variability. Cancer Epidemiol Biomarkers Prev 2002;11:1025-1032.

29 Clifford MN, van der Hooft JJ, Crozier A: Human studies on the absorption, distribution, metabolism, and excretion of tea polyphenols. Am J Clin Nutr 2013;98:1619S-1630S.

30 Clarke KA, Dew TP, Watson RE, Farrar MD, Osman JE, Nicolaou A, Rhodes LE, Williamson G: Green tea catechins and their metabolites in human skin before and after exposure to ultraviolet radiation. J Nutr Biochem 2016; 27:203-210.

31 Meng X, Sang S, Zhu N, Lu H, Sheng S, Lee MJ, Ho CT, Yang CS: Identification and characterization of methylated and ring-fission metabolites of tea catechins formed in humans, mice, and rats. Chem Res Toxicol 2002; 15:1042-1050.

32 Rhodes LE, Darby G, Massey KA, Clarke KA, Dew TP, Farrar MD, Bennett S, Watson RE, Williamson G, Nicolaou A: Oral green tea catechin metabolites are incorporated into human skin and protect against UV radiationinduced cutaneous inflammation in association with reduced production of pro-inflammatory eicosanoid 12-hydroxyeicosatetraenoic acid. Br J Nutr 2013;110:891-900.
33 Yang CS, Lee MJ, Chen L: Human salivary tea catechin levels and catechin esterase activities: implication in human cancer prevention studies. Cancer Epidemiol Biomarkers Prev 1999;8:83-89.

34 Badhani B, Sharma N, Kakkar R: Gallic acid: a versatile antioxidant with promising therapeutic and industrial applications. RSC Advances 2015;5:27540-27557.

35 Sanchez-Patan F, Chioua M, Garrido I, Cueva C, Samadi A, Marco-Contelles J, Moreno-Arribas MV, Bartolome B, Monagas M: Synthesis, analytical features, and biological relevance of 5 - $\left(3^{\prime}, 4^{\prime}\right.$-dihydroxyphenyl)- $\gamma$-valerolactone, a microbial metabolite derived from the catabolism of dietary flavan-3-ols. J Agric Food Chem 2011;59:7083-7091.

36 Chow HH, Cai Y, Hakim IA, Crowell JA, Shahi F, Brooks CA, Dorr RT, Hara Y, Alberts DS: Pharmacokinetics and safety of green tea polyphenols after multiple-dose administration of epigallocatechin gallate and polyphenon $\mathrm{E}$ in healthy individuals. Clin Cancer Res 2003;9:3312-3319.

37 Heinrich U, Moore CE, De Spirt S, Tronnier $\mathrm{H}$, Stahl W: Green tea polyphenols provide photoprotection, increase microcirculation, and modulate skin properties of women. J Nutr 2011;141:1202-1208.

38 Farrar MD, Nicolaou A, Clarke KA, Mason S, Massey KA, Dew TP, Watson RE, Williamson G, Rhodes LE: A randomized controlled trial of green tea catechins in protection against ultraviolet radiation-induced cutaneous inflammation. Am J Clin Nutr 2015;102:608615.

39 Clement Y: Can green tea do that? A literature review of the clinical evidence. Prev Med 2009;49:83-87.

40 Mereles D, Hunstein W: Epigallocatechin3-gallate (EGCG) for clinical trials: more pitfalls than promises? Int J Mol Sci 2011;12: 5592-5603.

41 Maiani G, Serafini M, Salucci M, Azzini E, Ferro-Luzzi A: Application of a new high-performance liquid chromatographic method for measuring selected polyphenols in human plasma. J Chromatogr B Biomed Sci Appl 1997;692:311-317.

42 Del Rio D, Calani L, Cordero C, Salvatore S, Pellegrini N, Brighenti F: Bioavailability and catabolism of green tea flavan-3-ols in humans. Nutrition 2010;26:1110-1116.

43 Calani L, Del Rio D, Luisa Callegari M, Morelli L, Brighenti F: Updated bioavailability and $48 \mathrm{~h}$ excretion profile of flavan-3-ols from green tea in humans. Int J Food Sci Nutr 2012; 63:513-521.

$44 \mathrm{Wu}$ AH, Tseng CC, Van Den Berg D, Yu MC: Tea intake, COMT genotype, and breast cancer in Asian-American women. Cancer Res 2003;63:7526-7529.

45 Naumovski N, Blades BL, Roach PD: Food inhibits the oral bioavailability of the major green tea antioxidant epigallocatechin gallate in humans. Antioxidants (Basel) 2015;4:373393.
46 Maeda-Yamamoto M, Ema K, Shibuichi I: In vitro and in vivo anti-allergic effects of "Benifuuki" green tea containing $O$-methylated catechin and ginger extract enhancement. Cytotechnology 2007;55:135-142.

47 Masuda S, Maeda-Yamamoto M, Usui S, Fujisawa T: "Benifuuki" green tea containing $o$ methylated catechin reduces symptoms of Japanese cedar pollinosis: a randomized, double-blind, placebo-controlled trial. Allergol Int 2014;63:211-217.

48 Haag SF, Taskoparan B, Darvin ME, Groth N, Lademann J, Sterry W, Meinke MC: Determination of the antioxidative capacity of the skin in vivo using resonance Raman and electron paramagnetic resonance spectroscopy. Exp Dermatol 2011;20:483-487.

49 Lohan BS, Lauer A-C, Arndt S, Friedrich A, Tscherch K, Haag FS, Darvin EM, Vollert H, Kleemann A, Gersonde I, Groth N, Lademann J, Rohn S, Meinke CM: Determination of the antioxidant status of the skin by in vivoelectron paramagnetic resonance (EPR) spectroscopy. Cosmetics 2015;2:286-301.

50 Plonka PM: Electron paramagnetic resonance as a unique tool for skin and hair research. Exp Dermatol 2009;18:472-484.

51 Fuchs J, Groth N, Herrling T, Zimmer G: Electron paramagnetic resonance studies on nitroxide radical 2,2,5,5-tetramethyl-4-piperidin-1-oxyl (TEMPO) redox reactions in human skin. Free Radic Biol Med 1997;22:967976.

52 Lademann J, Meinke MC, Sterry W, Darvin ME: Carotenoids in human skin. Exp Dermatol 2011;20:377-382.

53 Darvin ME, Gersonde I, Meinke M, Sterry W, Lademann J: Non-invasive in vivo determination of the carotenoids beta-carotene and lycopene concentrations in the human skin using the Raman spectroscopic method. J Phys D 2005;38:2696.

54 Darvin ME, Gersonde I, Albrecht H, Meinke $\mathrm{M}$, Sterry W, Lademann J: Non-invasive in vivo detection of the carotenoid antioxidant substance lycopene in the human skin using the resonance Raman spectroscopy. Laser Phys Lett 2006;3:460-463.

55 Polovka M, Brezová V, Stasko A: Antioxidant properties of tea investigated by EPR spectroscopy. Biophys Chem 2003;106:39-56.

56 Moskaug J, Carlsen H, Myhrstad MC, Blomhoff R: Polyphenols and glutathione synthesis regulation. Am J Clin Nutr 2005;81:277S-283S.

57 Kashyap D, Mittal S, Sak K, Singhal P, Tuli HS: Molecular mechanisms of action of quercetin in cancer: recent advances. Tumour Biol 2016;37:12927-12939.

58 Basu A, Betts NM, Mulugeta A, Tong C, Newman E, Lyons TJ: Green tea supplementation increases glutathione and plasma antioxidant capacity in adults with the metabolic syndrome. Nutr Res 2013;33:180-187.

59 Fuchs J, Herrling T, Groth N: Detection of free radicals in skin: a review of the literature and new developments. Curr Probl Dermatol 2001;29:1-17. 
60 Meinke MC, Lauer A-C, Haag SF, Darvin ME, Groth N, Lademann J: Cutaneous radical scavenging effects of orally administered antioxidants measured by electron paramagnetic resonance spectroscopy. e-SPEN J 2012; 7:e160-e166.

61 Lauer AC, Groth N, Haag SF, Darvin ME, Lademann J, Meinke MC: Dose-dependent vitamin $\mathrm{C}$ uptake and radical scavenging activity in human skin measured with in vivo electron paramagnetic resonance spectroscopy. Skin Pharmacol Physiol 2013;26:147-154.

62 Meinke MC, Friedrich A, Tscherch K, Haag SF, Darvin ME, Vollert H, Groth N, Lademann J, Rohn S: Influence of dietary carotenoids on radical scavenging capacity of the skin and skin lipids. Eur J Pharm Biopharm 2013;84:365-373.

63 Zhang X, Wu Z, Weng P: Antioxidant and hepatoprotective effect of (-)-epigallocatechin 3-O-(3-O-methyl) gallate (EGCG3"'Me) from Chinese oolong tea. J Agric Food Chem 2014;62:10046-10054.
64 Chen C, Yu R, Owuor ED, Kong AN: Activation of antioxidant-response element (ARE), mitogen-activated protein kinases (MAPKs) and caspases by major green tea polyphenol components during cell survival and death. Arch Pharm Res 2000;23:605-612.

65 Darvin ME, Patzelt A, Knorr F, Blume-Peytavi U, Sterry W, Lademann J: One-year study on the variation of carotenoid antioxidant substances in living human skin: influence of dietary supplementation and stress factors. J Biomed Opt 2008;13:044028.

66 Lademann J, Köcher W, Yu R, Meinke MC, Na Lee B, Jung S, Sterry W, Darvin ME: Cutaneous carotenoids: the mirror of lifestyle? Skin Pharmacol Physiol 2014;27:201.

67 Hayashi T: Conversion of psychological stress into cellular stress response: roles of the sigma-1 receptor in the process. Psychiatry Clin Neurosci 2015;69:179-191.
68 Maher P: The effects of stress and aging on glutathione metabolism. Ageing Res Rev 2005;4:288-314.

69 Princen HM, van Duyvenvoorde W, Buytenhek R, Blonk C, Tijburg LB, Langius JA, Meinders AE, Pijl H: No effect of consumption of green and black tea on plasma lipid and antioxidant levels and on LDL oxidation in smokers. Arterioscler Thromb Vasc Biol 1998; 18:833-841.

70 Zink A, Traidl-Hoffmann C: Green tea in dermatology - myths and facts. J Dtsch Dermatol Ges 2015;13:768-775.

71 Manach C, Scalbert A, Morand C, Rémésy C, Jiménez L: Polyphenols: food sources and bioavailability. Am J Clin Nutr 2004;79:727747.

72 Alonso C, Rubio L, Touriño S, Martí M, Barba C, Fernández-Campos F, Coderch L, Parra JL: Antioxidative effects and percutaneous absorption of five polyphenols. Free Radic Biol Med 2014;75:149-155. 